University of Nebraska - Lincoln

DigitalCommons@University of Nebraska - Lincoln

Publications, Agencies and Staff of the U.S.

Department of Commerce

U.S. Department of Commerce

2010

\title{
Adapting MODIS-derived LAI and fractional cover into the RAMS in East Africa
}

\author{
Nathan Moore \\ Michigan State University \\ Nathan Torbick \\ Applied GeoSolutions, LLC \\ Brent Lofgren \\ NOAA/GLERL \\ Jing Wang \\ University of Illinois at Chicago \\ Bryan Pijanowski \\ Purdue University \\ See next page for additional authors
}

Follow this and additional works at: https://digitalcommons.unl.edu/usdeptcommercepub

Part of the Environmental Sciences Commons

Moore, Nathan; Torbick, Nathan; Lofgren, Brent; Wang, Jing; Pijanowski, Bryan; Andresen, Jeffrey; Kim, Dong-Yun; and Olson, Jennifer, "Adapting MODIS-derived LAI and fractional cover into the RAMS in East Africa" (2010). Publications, Agencies and Staff of the U.S. Department of Commerce. 293.

https://digitalcommons.unl.edu/usdeptcommercepub/293

This Article is brought to you for free and open access by the U.S. Department of Commerce at DigitalCommons@University of Nebraska - Lincoln. It has been accepted for inclusion in Publications, Agencies and Staff of the U.S. Department of Commerce by an authorized administrator of DigitalCommons@University of Nebraska - Lincoln. 


\section{Authors}

Nathan Moore, Nathan Torbick, Brent Lofgren, Jing Wang, Bryan Pijanowski, Jeffrey Andresen, Dong-Yun Kim, and Jennifer Olson 


\title{
Adapting MODIS-derived LAI and fractional cover into the RAMS in East Africa
}

\author{
Nathan Moore, ${ }^{a *}$ Nathan Torbick, ${ }^{\mathrm{b}}$ Brent Lofgren, ${ }^{\mathrm{c}}$ Jing Wang, ${ }^{\mathrm{d}}$ Bryan Pijanowski, ${ }^{\mathrm{e}}$ \\ Jeffrey Andresen, ${ }^{\mathrm{a}}$ Dong-Yun Kim ${ }^{\mathrm{f}}$ and Jennifer Olson ${ }^{\mathrm{a}}$ \\ a Department of Geography, Michigan State University, MI, USA \\ b Applied GeoSolutions, LLC, 87 Packers Falls Road, Durham, NH 03824, USA \\ ${ }^{c}$ NOAA/GLERL,4840 S. State Rd, Ann Arbor, MI 48108-9719, USA \\ ${ }^{\mathrm{d}}$ Department of Mathematics, Statistics and Computer Science, University of Illinois - Chicago, Chicago, IL, USA \\ e Department of Forestry and Natural Resources, Purdue University, West Lafayette, IN, USA \\ ${ }^{\mathrm{f}}$ Department of Statistics, Virginia Tech, VA, USA
}

\begin{abstract}
Land cover and its associated biophysical parameters govern many land-atmosphere interactions. Several previous studies have demonstrated the utility of incorporating satellite-derived observations of land cover into climate models to improve prediction accuracy. In the developing world where agriculture is a primary livelihood, a better understanding of seasonal variability in precipitation and near-surface temperature is critical to constructing more effective coping strategies for climate changes and food security. However, relatively few studies have been able to assess the impacts of improved surface parameterisation on these variables and their seasonality. Using moderate resolution imaging spectroradiometer (MODIS)-derived products, we sought to address this shortcoming by adapting leaf area index (LAI) and vegetative fractional cover (FC) products, along with an improved representation of the land surface (i.e. land use land cover) into the Regional Atmospheric Modelling System in East Africa to evaluate the effect improved representations would have on simulated precipitation and land surface temperature (LST). In particular, we tested the hypothesis that improved phenological parameterisations could reduce error in precipitation and LST under dramatically different atmospheric conditions. The model was used to simulate dry/normal/wet rainfall years of 2000, 2001, and 2002 (respectively) in order to understand biases in this parameterisation under different boundary conditions. Our results show a dramatic improvement in LST simulation due to the use of the improved representations (spline functions) during most of the year, both spatially and temporally. Annual precipitation, which is dependent upon a much greater variety of surface and atmospheric characteristics, did not improve as much by adopting the spline representations of LAI and FC; the results were more equivocal. However, seasonal timing of precipitation improved in some areas, and this improvement has important consequences for integrated climate-agriculture assessments. Copyright (c) 2009 Royal Meteorological Society
\end{abstract}

KEY WORDS climate modelling; MODIS; LAI; fractional cover; RAMS

Received 11 September 2008; Revised 15 May 2009; Accepted 28 July 2009

\section{Introduction}

\subsection{Land-atmosphere interactions}

The pace and global reach of human alterations of the landscape have accelerated in the last century. The term 'Anthropocene' (Crutzen and Stoermer, 2000) refers not only to the geological context of these transformations, but also to the consequences of such massive humandriven changes to the land surface. Over the last three centuries, humans have expanded agriculture to encompass over $40 \%$ of all arable global land (Foley et al., 2005). The consequences of such changes include alterations to the physical characteristics of landscapes like albedo that dramatically alter the surface energy budget. Scaled to regional and global extents, many believe (Marland et al., 2003) that changes in surface characteristics

\footnotetext{
* Correspondence to: Nathan Moore, Department of Geography, Michigan State University, MI, USA. E-mail: moorena@msu.edu
}

may equal or exceed those of greenhouse gas forcings. Radiative forcings due to changes in land use and land cover have been shown to be significant and spatiotemporally complex for the United States (Barnes and Roy, 2008). Clearly, regional landscape assessments are a vital piece of understanding climate change.

The interaction of climate change and land use change occurs at several interfaces. Seneviratne et al. (2006) showed that land-atmosphere feedbacks exert strong control on regional and local temperature variability, thus impacting many important ecosystem services such as agricultural production. They argued that as warmer temperature regimes move northwards in Europe, the types and diversity of agricultural crops grown are likely to shift as a result of temperature and precipitation changes. Other researchers have found that conversion of grassland to irrigated cotton farms in semi-arid areas is likely related to altered precipitation patterns (Moore and 
Rojstaczer, 2002), and clouds and convection are linked to spatial heterogeneities in land cover (Rabin et al., 1990; Carleton et al., 1994). Weaver and Avissar (2001) have shown that surface heterogeneities created by agricultural conversion exert a direct and significant effect on rainfall. Other modelling studies (Lofgren, 1995; Roy and Avissar, 2002; Oyama and Nobre, 2003; Hales et al., 2004; Diffenbaugh et al., 2005; Voldoire et al., 2007) have demonstrated that landscape changes can significantly alter atmospheric dynamics. Assimilating moderate resolution imaging spectroradiometer (MODIS) phenology improved performance in the community land model (Lawrence and Chase, 2007); thus an extension to climate models is a natural one. However, relatively few studies have examined and connected the complex relationships between land cover/land use change (LCLUC), phenology, and climate change to agriculture. In the developing world, agricultural production is mostly for sustenance; thus, understanding these is of critical importance.

One of the key linkages between climate and land cover change concerns the physical characteristics of the surface that are dynamically related to plant phenology. The traditional manner of handling land-climate feedbacks via phenological dynamics is to represent plant phenology using simple time-dependent functions (Pitman, 2003). In Regional Atmospheric Modelling System (RAMS) version 4.4, for example, a plant phenology routine, called LEAF-2 (Walko et al., 2000), treats phenological dynamics using a single sinusoidal curve. However, many tropical ecosystems have a bimodal phenological pattern that is driven by short and long rain cycles. Although unimodal seasonal rainfall patterns dominate as one moves north and south away from the Equatorial latitudes, some regions near the Equator exhibit a bimodal pattern; modelling such regions requires a 'mixed' phenological model. Simply using a single year's phenology would not be suitable for many regions that experience significant interannual variability in phenology.
There are several approaches one can take to address the shortcomings of the LEAF-2 parameterisation in RAMS. First, LEAF-2 could be replaced with a process-oriented model, such as Century, that relates physiological outcomes to biophysical characteristics such as leaf area index (LAI; Parton et al., 1998). A second approach is to modify the single cycle curve to include a bimodal curve or some other correlations or look up table that more appropriately characterises plant dynamics for specific regions.

A third approach, explored in more detail here, is to use remote sensing imagery that provides LAI and FC (fractional cover) as inputs to RAMS. Because remote sensing supplies high-resolution information across large areas, aggregating this information to coarser scale regional models presents challenges. In this case, RAMS was run at a grid spacing of $36 \mathrm{~km}$; MODIS data used here were of $1 \mathrm{~km}$ resolution. Furthermore, the spatial variability of the biophysical variables means that a more complex model that includes location could improve situations where bimodal and unimodal phenological patterns exist within a single simulation domain.

\subsection{East African climate}

To help put land change in perspective, an explanation of some key aspects of East African climate is warranted. Despite straddling the Equator, East Africa is predominantly semi-arid in the highland areas. With desert in northeastern Kenya, high rainfall at higher elevations, and wetter conditions near Lake Victoria and the Indian Ocean coast, East Africa spans a broad variety of climate types and precipitation regimes (e.g. Figure 1, Indeje et al., 2000) which is also reflected in its vegetation cover. The main agricultural areas of Kenya, Uganda, and Tanzania receive rain in two distinct seasons locally referred to as the 'long rains' (March-May) and the 'short rains' (October-November). The long rains provide more rainfall than the short rains and have a lower interannual variability (Camberlin and Okoola,

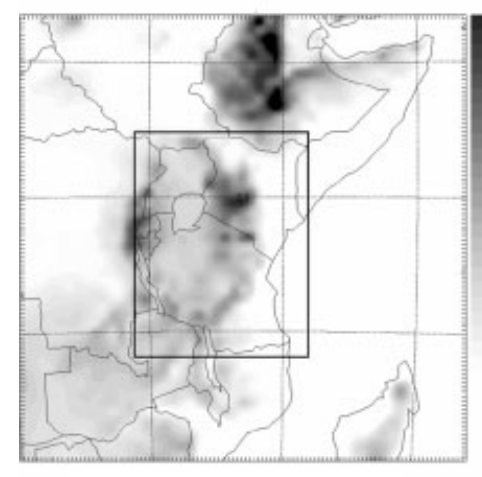

Topography

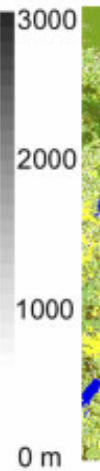

$0 \mathrm{~m}$

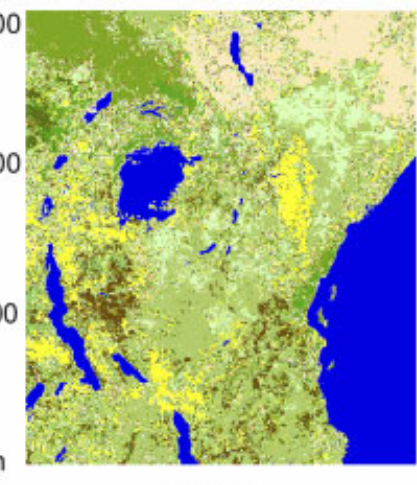

OGE
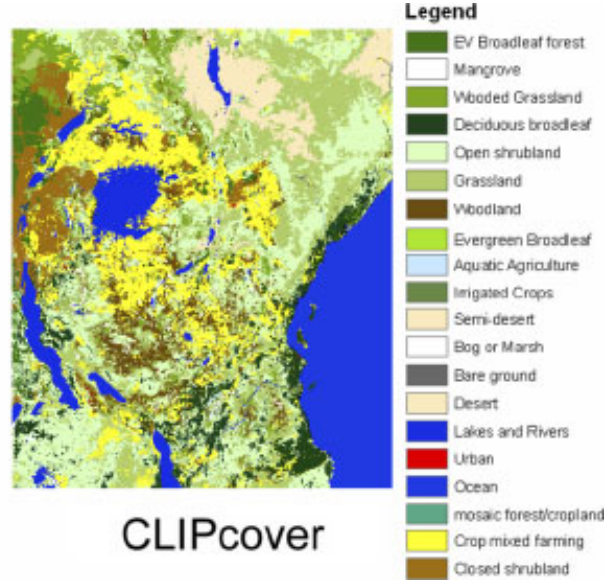

Figure 1. Topography (metres) of the entire domain used in the atmospheric model (left panel). The inset box shows the area of interest in this study and other CLIP project activities. Olson Global Ecosystem (centre panel) and ClipCover (right panel) land cover classifications contain major differences in areas classified as agriculture (yellow) and mixed agriculture/grazing (brown). This figure is available in colour online at wileyonlinelibrary.com/journal/joc 
2003), but generally, the arrival of the short rains is more predictable. Outside the region of bimodal short rains and long rains, a more unimodal rainfall distribution is found (i.e. southern Tanzania and northern Kenya/Uganda).

Research on the long rains and, most particularly, on the short rains have shown sensitivities to the Indian Ocean dipole (IOD) using observations (Black et al., 2003; Camberlin and Okoola, 2003(long rains only)] and general circulation models (Behera et al., 2005(short rains only), Conway et al., 2007). Although El Niño/Southern oscillation (ENSO) teleconnections show some correlation to observed climate (Indeje et al., 2000; Schreck and Semazzi, 2004) and vegetation variability (Plisnier et al., 2000), observational (Black et al., 2003) and modelling (Latif et al., 1999) studies point to a more robust relationship between East Africa's climate and the IOD. At finer timescales, the Madden-Julian oscillation is 'the dominant mode of intraseasonal variability' for East Africa (Pohl et al., 2005). Regional modelling efforts by Sun et al. (1999) indicate that the Indian ocean influence is dominant for the short rains in the region, but during wet years, ENSO events are strongly correlated to high short rains. The Indian Ocean influence appears to be more apparent for extreme wet and dry events (Okoola, 1999). These large-scale forcings, although influential, are mediated by mesoscale processes related to a variety of sources. For example, East Africa's complex topography exerts a statistically strong influence on boundary layer processes, and thus also on rainfall (Oettli and Camberlin, 2005). In addition, coastal climate differentiates itself from the highland climate due to small-scale convection from the land/sea breeze (Camberlin and Planchon, 1997).

The purpose of this paper is to present the results of land-climate interaction simulations where a mixed phenological model was developed using MODIS imagery. To do this, we briefly describe the methodology for an improved representation of regionally specific LAI and FC that uses a statistical spline model of MODIS imagery that captures both unimodal and bimodal phenological patterns across the Equatorial region of East Africa. We present, in Section 2, an overview of the regional climate model configuration, a description of the datasets used, the parameterisation of LAI and FC with splines, and some critical aspects of our experimental design. Section 3 covers the impacts of our new LAI and FC parameterisations compared to the 'default' LEAF-2 parameterisations, and Section 4 contains a discussion of our new methodology.

\section{Experimental design and method}

\subsection{Study area}

Our simulations were conducted over a sub-Saharan region of East Africa that includes five countries in their entirety (Kenya, Uganda, Tanzania, Burundi, and Rwanda) and portions of seven countries (Somalia, Ethiopia, Sudan, Democratic Republic of Congo, Malawi,
Mozambique, and Zimbabwe). This region spans $28^{\circ} \mathrm{E}$ to $42^{\circ} \mathrm{E}$ and $12^{\circ} \mathrm{S}$ to $6^{\circ} \mathrm{N}$ (Figure 1). Also included in the region are several large East African Great Lakes such as Lake Victoria, Lake Malawi, and Lake Tanganyika. In this region, rainfall patterns are complex; from Uganda to Mombasa, a bimodal rainfall pattern of long rains (March-May) and short rains (October-November) brings most rainfall to the highly productive highlands. To the north (Northern Kenya) and south (most of Tanzania) of this bimodal band, rainfall is more unimodal and follows the ITCZ. In Northern Kenya, rainfall arrives in June-August and in most of Tanzania, rainfall comes during November-February.

\subsection{Model configuration}

We used the RAMS version 4.4 (Pielke et al., 1992; Cotton et al., 2003), including the LEAF-2 module, for the representation of surface-vegetation processes (Walko et al., 2000). RAMS is a three-dimensional, nonhydrostatic, general-purpose atmospheric simulation system which solves the equations of motion, heat, moisture, and mass continuity in a terrain following the 'sigma-z' coordinate system. Certain aspects of model configuration exert a strong influence on the model solution, and we explored several settings and parameterisations. We used the Mellor-Yamada closure for turbulence (Mellor and Yamada, 1982), the Kain-Fritsch scheme (Kain and Fritsch, 1993) with modifications for convective parameterisation, and the radiation parameterisation of Chen and Cotton (1987). Soil properties from Clapp and Hornberger (1978) were used in conjunction with a soil model that handles temperature and moisture (Deardorff, 1978; Tremback and Kessler, 1985). The model was configured with two grids: an outer grid at $108 \mathrm{~km}$ grid spacing, and an inner nested grid at $36 \mathrm{~km}$ grid spacing.

RAMS simulations were extensively tuned during an 8-week period (April through May) for 2000, 2001, and 2002 by varying the gamma function parameters for microphysics (which generates rainfall) and for topographic and cloud base parameters in the Kain-Fritsch scheme. Rainfall parameters were adjusted to best match observed data (among the parameters explored were cloud condensation nucleus size, gamma function shape parameter, number of nuclei, and the Kain-Fritsch topographic coefficient). A onedimensional lake model for Lake Victoria was developed following Hostetler et al. (1993) given the strong atmospheric influence of Lake Victoria on the surrounding area (Anyah et al., 2006). Weekly sea surface temperatures were obtained from the NOAA OISST database (http://www.cdc.noaa.gov/cdc/data.noaa.oisst.v2.html; Reynolds et al., 2002). The simulation years 2000, 2001, and 2002 were chosen as drier than normal, near normal, and wetter than normal as compared with 30-year (1973-2002) mean annual rainfall estimates from the Climate Research Unit dataset (www.cru.uea.ac.uk/cru/ data/). Simulations started on 1 July 1999, and simulation data prior to January 2000 were omitted as 'spin-up'. 
Soil moisture was initialised for 1 July 1999 taken from National Centers for Environmental Prediction (NCEP) reanalysis data. This allowed for the model to integrate forward and attain 'equilibrium' with the atmosphere by January 2000. Winds were also checked for consistency. During March-May, consistent northeasterly winds advected moisture into the East African area; together with the Low over the Congo basin and enhanced convection along shorelines, a strong low-level convergence zone developed from central Uganda through the highland areas. Southeasterly winds are evident for June-August in the model, consistent with the East African low-level jet. At $\sim 1.2 \mathrm{~km}$ and generally following the coast, these winds play a part in the largescale monsoon winds flowing towards India (Indeje and Anyamba, 1998).

Land surface parameterisations in RAMS include functional estimates of albedo, FC, LAI, rooting depth, stomatal conductance, and other biophysical characteristics (i.e. LEAF-2; Walko et al., 2000). In order for the regional model to be globally applicable in diverse areas, our initial approach was to provide simple, general parameterisations. However, regional-specific observations of LAI and FC are superior representations of land surface characteristics; this was demonstrated clearly by Lu and Shuttleworth (2002; hereafter, LS02). Since East Africa is somewhat unique as a semi-arid region bounding the Equator, the general 'default' parameterisations of LAI and FC are highly unsuitable. Here we show test results from three numerical experiments: first, the Olson Global Ecosystem (OGE) land cover with default LEAF-2 phenology (Figure 1, centre); second, a regionalspecific land cover that includes socioeconomic information, called CLIPcover (CC; Figure 1, right); and third, CLIPcover land cover with MODIS-derived regionalspecific phenologies for vegetation (CCV). The labels OGE, CC, and $\mathrm{CCV}$ are hereafter used to refer to these experiments, respectively. All other climate model boundary conditions for the simulations were derived from NCEP atmospheric reanalysis product (Kalnay et al., 1996).

\subsection{LULC parameterisation and datasets}

We used two land cover datasets as part of our experimental design. The first was the OGE (Olson et al., 1985) land cover dataset derived from AVHRR (advanced very high resolution radiometer) and frequently used in atmospheric simulations. The second was CLIPcover, hybrid land cover dataset (Torbick et al., 2006), which is based on a series of product assessments (Ge et al., 2005; Torbick et al., 2005; Olson et al., 2007) combined with optimal classification products available for East Africa. The CLIPcover land use land cover (LULC) dataset integrates the strengths of Africover (www.africover.org; Latham, 2001) and Global Land Cover 2000 (GLC2000, Mayaux et al., 2004) datasets. Both datasets are based on the hierarchical land cover classification system for land surface categories (Di Gregorio and Jansen, 2005).
Thus, the hybrid database combines land uses from Africover - social and economic variables on the land surface - with land covers from GLC2000, with case study sites used to verify which classes were more accurate in each dataset. An important factor in climate models, LULC, serves as a framework for many biophysical attributes that influence energy balance and model output (Ge et al., 2007).

We used a suite of land surface products developed by the NASA MODIS land science team including LAI, Enhanced Vegetation Index (EVI), and land surface temperature (LST) (Huete et al., 2002; Justice et al., 2002; Wan et al., 2004a; Wang et al., 2004). The MODIS instrument on-board the sun-synchronous Terra satellite platform collects measurements in 36 spectral bands with moderate spatial $(\sim 250 \mathrm{~m}-1 \mathrm{~km})$ resolutions. FC was derived from composite 16-day MODIS EVI products (MOD13A3v4). These MODIS-derived products have undergone rigorous development and calibration for dryland and savanna ecosystems. Huete et al. (2002) evaluated MODIS radiometric and biophysical precision and found dynamic range and sensitivity to perform well and with higher fidelity in semi-arid grasslands and savanna sites at the Walnut Gulch Experimental Watershed in Arizona, the La Jornada Experimental Range in New Mexico, and the Brazilian cerrado. Huete et al. (2002) noted that maximum error was found in situations when only one pixel was used in a compositing period which was avoided in this study by using the climate modeling grid $(\mathrm{CMG})$ composited products. To generate $\mathrm{FC}$ products for East Africa, a linear un-mixing approach using selected end-member regions was applied to the MODIS EVI products for 2000-2004. This approach uses the selected end-members to un-mix the portion of a pixel into two distinct components: canopy/vegetation and soil/bare ground. End-members were selected from dense forest in the Congo Forested basin and the dry, arid savanna in northern Kenya. This linear un-mixing approach has been validated across several ecosystems and is used widely to generate FC (Gutman and Ignatov, 1998; Qi et al., 2000). LAI is defined as the surface area of leaf per unit area of ground, and influences surface flux exchanges and other planetary boundary interactions. LAI products (MOD15v4) were obtained at 8-day composited intervals for 2000-2004. The MODIS LAI algorithm incorporates ancillary surface measurements such as LULC (Knyazikhin et al., 1999). MODIS LAI has been validated in a range of ecosystem with accuracies on the order of \pm 0.5 LAI (Wang et al., 2004).

For evaluation of RAMS performance and linkage to net primary productivity/crop models, we focused on two important variables for the region: precipitation and landsurface temperature, with an emphasis on seasonality. To evaluate the performance of RAMS for these two variables, we used precipitation data from the Tropical Rainfall Measurement Mission (TRMM) and MODIS LST. For assessment we used the MODIS LST/Emissivity 8-day L3 Global 0505 CMG (MOD11C2) products (ftp://modular.nascom.nasa.gov/pub/LatestFilespecs/ 
collection5/). These were aggregated up to the coarser $36 \mathrm{~km}$ resolution of the climate model. We matched the timing of the satellite overpass to the output of RAMS for accurate comparisons. LST accuracy is reported to be within $1 \mathrm{~K}$ under clear-sky conditions in a range of ecosystems including semi-arid and dryland ecosystems (Wan et al., 2002, 2004a, 2008). MODIS LST has been utilised extensively in dryland and savanna ecosystems for monitoring surface temperature and biophysical conditions. For example, Wan et al. (2004b) utilised MODIS LST to monitor drought in the southern Great Plains of the United States and found the products derived from MODIS LST to closely correlate with precipitation and departure from monthly averages. Overall, its sensitivity in semi-arid grasslands and utility for monitoring land surface conditions were highlighted. TRMM estimates, based on both active and passive microwave instruments, were used for comparison with simulated precipitation. TRMM estimates employ the visible and infrared scanner and TRMM microwave imager instrumentation. Data used included the TRMM 3B42 v6 3-h data on a $0.25^{\circ} \times 0.25^{\circ}$ grid for assessing domain-averaged and gridded RAMS rainfall output. Simulated LST was calculated from upward longwave radiation using the Stefan-Boltzmann law and model emissivity per pixel.

\subsection{Construction of splines for LAI and FC} parameterisation

LAI and FC are not independent; at LAI values below $\sim 2$, FC and LAI are highly correlated, but this relationship breaks down as LAI increases above 2 (Qi et al., 2000). Thus, different parameterisations were needed for both variables. We constructed spline functions of the 10 most common land cover classes in the study area which covered $89 \%$ of the domain. Comparisons of the default versus spline LAI and FC are shown in Figures 2 and 3. Although this process washes out some interannual variability, it was employed to more accurately capture the seasonal greening and senescence of the area
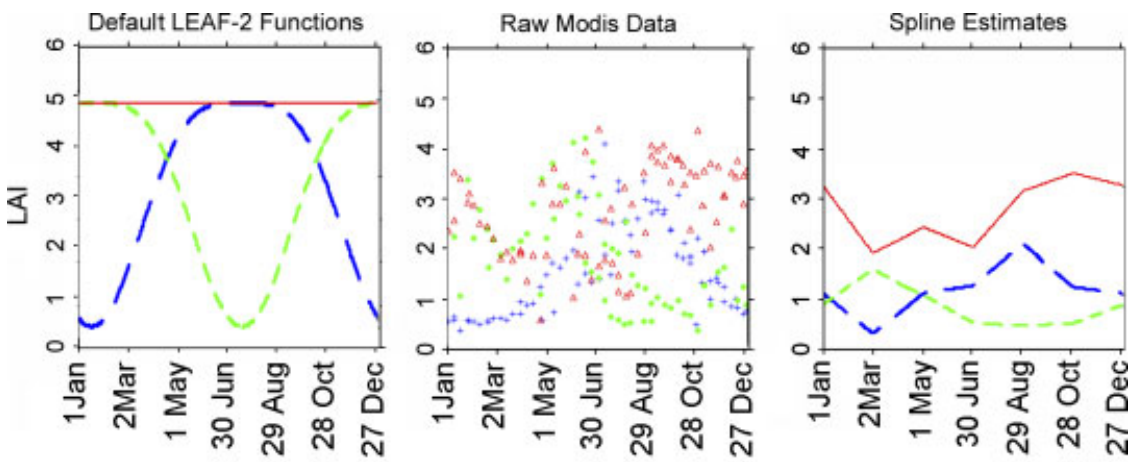

Rainfed Herbaceous Crop

at $+5^{\circ} \quad$ at Equator

- at $-5^{\circ}$

Figure 2. Example of the spline functions for the rainfed herbaceous crop cover type used in this numerical experiment at three different latitudes The $x$-axis is Julian date. The default look-up values (shown at left) exhibit larger annual variation and lack the seasonal pattern details evident in the MODIS data (centre) and the resulting splines (right). The middle figure average data at several longitudes; the resulting functions represent an average over the same longitude range. This figure is available in colour online at wileyonlinelibrary.com/journal/joc

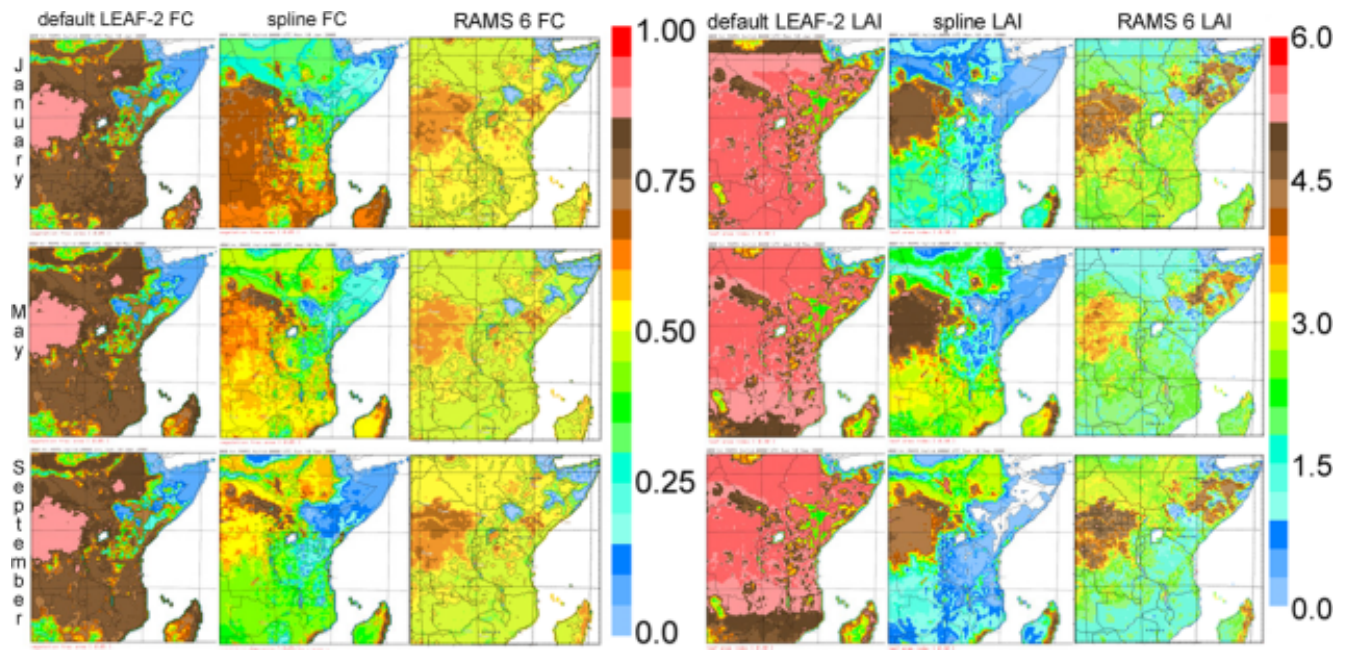

Figure 3. Default and constructed spline representations of FC (left panels) and LAI (right panels) for January, May, and September over the study domain. Also shown for comparison are FC and LAI using RAMS 6 NDVI functions. Spatial distribution and seasonality are more accurately represented using the spline functions or NDVI-derived RAMS 6 functions; the spline functions were constructed to be used in future climate projections. This figure is available in colour online at wileyonlinelibrary.com/journal/joc 
while still treating LAI and FC as annual functions. The splines concept uses piecewise polynomials to fit data directly via least-squares procedures. In particular, there is no rigid assumption about the function shape. Detailed descriptions on construction and asymptotic properties of polynomial splines are available (Huang, 2003; Wang and Yang, 2009). In RAMS, FC directly influences albedo. However, for this study, the seasonal changes in albedo were simply constructed from the default RAMS seasonality with the midseason albedo defined by annually averaged MODIS data.

\subsection{Simulations}

To assess the performance of our new model, we executed totally nine simulations: three for the 'baseline' OGE landcover/default LAI and FC; three for the default LAI and FC parameterisations used with CLIPcover; and three for the new set of LAI and FC spline representations illustrated in Figures 2 and 3. They are as follows:

- OGE: years 2000, 2001, 2002

- CC: years 2000, 2001, 2002

- CCV: years 2000, 2001, 2002

Our hypothesis was that improved landscape representations together with improved general biophysical characteristics will reduce both annual error and seasonal error (in particular) for our simulations. We sought to quantify not only the annual average errors and domainaveraged variability, but also the seasonal differences between the resulting climate outputs (primarily temperature and precipitation from the crop model) and the more localised effects in areas that are heavily populated and/or important areas of agricultural activity. Again, OGE uses OGE land cover with RAMS default seasonal cycles of vegetation parameters; CC uses our ClipCover hybrid land cover with default seasonal cycles of vegetation parameters; and CCV uses ClipCover but with seasonal cycles derived from MODIS data.

\section{Results}

\subsection{Temperature}

Results of the LST comparison are presented first in terms of average differences with observed MODIS LST across the entire domain, and then progress to seasonal differences and agriculturally focused impacts of the new parameterisation. The MODIS LST products have been extensively refined and validated to provide precise and accurate information. Wan et al. (2004b) assessed MODIS LST against in situ field measurements for 20 clear-sky cases in 2000-2002 and found LST to be better than $1{ }^{\circ} \mathrm{C}$ in the range of $-10^{\circ} \mathrm{C}$ to $50^{\circ} \mathrm{C}$. Validation across multiple sites incorporating wide-ranging ecosystems and atmospheric conditions has consistently shown that MODIS LST products are within $\pm 1 \mathrm{~K}$. MODIS LST was within $\pm 1 \mathrm{~K}$ in the range $263-322 \mathrm{~K}$ for six cases in semi-arid and arid ecosystems (Wan et al., 2002). Further, comparisons between V5 LSTs and in situ values in 47 clear-sky cases (in the LST range from $-10^{\circ} \mathrm{C}$ to $58^{\circ} \mathrm{C}$ and atmospheric column water vapour range from 0.4 to $3.5 \mathrm{~cm}$ ) indicate that the accuracy of the LST product is better than $1 \mathrm{~K}$ in most cases ( 39 out of 47 ) and the root of mean squares (RMS) of differences is less than $0.7 \mathrm{~K}$ for all 47 cases or $0.5 \mathrm{~K}$ for all but the 8 cases with heavy aerosol loadings (Wan et al., 2008).

For LST validation we used MODIS 8-day composite LST. RAMS temperatures were calculated using upward longwave radiation, and results were very similar to the Jin method (Jin et al., 1997). Overall, results taken from the annual cases show only modest improvements with the $\mathrm{CC}$ and $\mathrm{CCV}$ simulations over the OGE simulations; however, the modifications reduced error more than OGE when measured at the monthly timescale, particularly during the growing seasons. Selected temperature statistics for MODIS 8-day LST and simulated temperature distributions are given in Table I. Little variation was seen annually with a noticeably improved correlation for the CCV case.

On the coarse regional scale, the improvements shown in $\mathrm{CCV}$ are comparable to LS02, albeit for a part of the world that has a complex growing season pattern. In addition, errors in land cover classification at finer scales may be masked by domain-averaged values and by longterm temporal averages. RAMS, at this grid spacing, is largely insensitive to this sub-grid scale variation. To look at the impacts of $\mathrm{CC}$ and $\mathrm{CCV}$ at finer temporal and spatial resolutions, we can examine the monthly domainaveraged pairwise RMS error (Table II) against MODIS

Table I. Selected temperature statistics for observed MODIS and model-simulated estimates for the study area during 2000, 2001, and 2002.

\begin{tabular}{|c|c|c|c|c|c|c|c|c|c|c|c|c|}
\hline & \multicolumn{4}{|c|}{2000} & \multicolumn{4}{|c|}{2001} & \multicolumn{4}{|c|}{2002} \\
\hline & MODIS & OGE & $\mathrm{CC}$ & CCV & MODIS & OGE & $\mathrm{CC}$ & $\mathrm{CCV}$ & MODIS & OGE & $\mathrm{CC}$ & $\mathrm{CCV}$ \\
\hline Mean & 289 & 292 & 293 & 293 & 292 & 291 & 293 & 292 & 289 & 292 & 294 & 292 \\
\hline Median & 303 & 304 & 303 & 304 & 302 & 302 & 304 & 304 & 302 & 303 & 305 & 303 \\
\hline SD & 6.2 & 4.6 & 5.6 & 5.0 & 6.0 & 4.1 & 5.4 & 4.1 & 5.7 & 4.4 & 5.1 & 5.3 \\
\hline IQR & 10 & 5 & 8 & 7 & 10 & 8 & 9 & 6 & 9 & 6 & 8 & 8 \\
\hline CORR & - & 0.39 & 0.42 & 0.51 & - & 0.30 & 0.21 & 0.38 & - & 0.29 & 0.16 & 0.42 \\
\hline
\end{tabular}

Statistics are over both time and space for the year given.

CORR, correlation coefficient with annual accumulated TRMM data; SD, standard deviation; IQR, interquartile range 
Table II. LST root mean square (RMS) error by month for the three simulations compared with MODIS.

\begin{tabular}{|c|c|c|c|c|c|c|c|c|c|c|c|c|}
\hline & \multicolumn{3}{|c|}{2000} & \multicolumn{3}{|c|}{2001} & \multicolumn{3}{|c|}{2002} & \multicolumn{3}{|c|}{ Mean } \\
\hline & OGE & $\mathrm{CC}$ & $\mathrm{CCV}$ & OGE & $\mathrm{CC}$ & $\mathrm{CCV}$ & OGE & $\mathrm{CC}$ & $\mathrm{CCV}$ & OGE & $\mathrm{CC}$ & $\mathrm{CCV}$ \\
\hline January & $\mathrm{X}$ & $\mathrm{x}$ & $\mathrm{x}$ & 7.5 & 6.7 & 6.5 & 5.7 & 6.0 & 6.2 & 6.6 & 6.4 & 6.4 \\
\hline February & $\mathrm{X}$ & $\mathrm{x}$ & $\mathrm{x}$ & 6.3 & 5.2 & 5.1 & 6.0 & 6.2 & 5.7 & 6.2 & 5.7 & 5.4 \\
\hline March & 5.9 & 5.8 & 5.6 & 6.5 & 6.0 & 5.9 & 6.4 & 7.2 & 6.2 & 6.3 & 6.3 & 5.9 \\
\hline April & 6.4 & 6.4 & 6.2 & 7.6 & 7.0 & 6.7 & 7.2 & 8.0 & 6.9 & 7.1 & 7.1 & 6.6 \\
\hline May & 5.3 & 5.8 & 5.8 & 4.2 & 5.5 & 5.5 & 5.5 & 6.4 & 5.2 & 5.0 & 5.9 & 5.5 \\
\hline June & 4.9 & 4.9 & 5.0 & 4.1 & 4.3 & 4.3 & 4.2 & 4.1 & 4.4 & 4.4 & 4.4 & 4.6 \\
\hline July & 4.9 & 4.8 & 4.8 & 4.2 & 4.1 & 4.2 & 5.2 & 4.3 & 4.8 & 4.8 & 4.4 & 4.6 \\
\hline August & 5.5 & 5.8 & 5.8 & 5.0 & 5.7 & 5.6 & 6.2 & 6.4 & 5.8 & 5.6 & 6.0 & 5.7 \\
\hline September & 5.9 & 5.5 & 5.5 & 5.0 & 4.6 & 4.5 & 6.2 & 5.0 & 5.5 & 5.7 & 5.0 & 5.2 \\
\hline October & 6.2 & 6.1 & 5.9 & 5.2 & 5.0 & 4.9 & 6.2 & 5.3 & 5.7 & 5.9 & 5.5 & 5.5 \\
\hline November & 6.9 & 6.4 & 6.1 & 4.7 & 4.9 & 4.7 & 6.0 & 6.4 & 5.8 & 5.9 & 5.9 & 5.5 \\
\hline December & 6.0 & 5.8 & 6.1 & 11.6 & 12.0 & 12.0 & 5.6 & 7.3 & 5.5 & 7.7 & 8.4 & 7.9 \\
\hline Average & 5.8 & 5.7 & 5.7 & 6.0 & 5.9 & 5.8 & 5.9 & 6.1 & 5.7 & 5.9 & 5.9 & 5.7 \\
\hline
\end{tabular}

RMS was applied to the difference maps, and the averaging was done over space.

Values in bold show the lowest RMS value for the given month. Mean values are shown at the right to interpret overall performance.

LST data. These results suggest that while CC and CCV are not consistently lower in RMS error versus MODIS throughout the year, seasonal differences and improved performance are evident, particularly in February-April and in November. Only in May, June, and August - when ITCZ rainfall is largely absent from the domain - were OGE temperatures more closely aligned with MODIS. Data in Figure 4 suggest that OGE tends to be cooler than $\mathrm{CC}$ and $\mathrm{CCV}$ during these months as a result of land cover distribution with relatively higher albedo during the dry months. MODIS sensors began gathering data in March 2000, hence there are no MODIS observations for January-February 2000.

Notably, CCV (Figure 4) had a slight warming effect compared to $\mathrm{CC}$, particularly during the long rains of March through early May in many of the regions. Modelled LST was generally hotter than MODIS LST in the regions with pronounced dry seasons (regions I, II, and III). More westerly regions VI and VII (southern Uganda and the Lake Victoria area) showed a cool bias in the model from September to January, associated with model overproduction of rainfall. This results from complex changes in both LAI and FC. During wet periods, higher LAI promotes cooling and FC is relatively high, and elevated soil moisture also plays a role in the cooling. However, the cooling effect is complicated by high variability in temperatures for different types of land covers, with the cooling effect being more prominent among grassland classes than forest or shrub classes. The reduction in domain-averaged RMS error was less consistent for $\mathrm{CC}$, with systematically higher LST than MODIS for the first half of all three years. Much of the relatively higher temperature errors in $\mathrm{CC}$ and $\mathrm{CCV}$ occurred in semi-arid areas where livestock grazing is dominant or where little crop agriculture or mixed activity takes place (Figure 5). Overall, the splines produced lower LAI and FC for most land cover types - particularly at the Equator - and as a result, albedos were higher than their default seasonal values in the CC experiment. Generally, the default LAI and FC were higher than MODIS-derived values.

By sorting effects via the Indeje regions, we could then examine results as a function of land cover type. Generally, replacing savanna with agriculture should result in higher albedos and lower LST, but with more seasonal variability for agriculture. For example, land cover in region $\mathrm{V}$ is a mixture of savanna and agriculture, with more agriculture in CC. However, the CCV phenology exhibits a more dynamic range of green-up and senescence than under CC or OGE, leading to noticeable departures from CC and OGE LST during the May-November periods (Figure 4(b), region V). Given that soil moisture data for initialisation can have a 'memory' for several months in semi-arid areas (Oglesby et al., 2002), the early month discrepancies can in some part be attributed to inconsistencies in boundary forcings and soil moisture initialisation. Indeed, reliable soil moisture data are not available for these areas, and even ECMWF and NCEP soil moisture estimates disagree sharply in many places.

The increased error evident in central Tanzania in Figure 5 is possibly related to errors in heterogeneity associated with CLIPcover, as the complexity of the land surface there varies dramatically over short distances. CC and $\mathrm{CCV}$ performed worse than OGE in the low-altitude areas near the Indian Ocean coast; this is due mainly to increased forest cover under $\mathrm{CC}$ and not due to spline errors.

It is worth exploring the mechanisms behind the differences in LST accuracy, particularly in the case of CCV's new phenological representations. Of particular interest are differences in cloud cover and in the surface energy budget. Cloud cover differences between $\mathrm{CCV}$ and $\mathrm{CC}$ in Figure 6(a) averaged over the 3 years show increased cloudiness around Lake Victoria, with. Generally, the splines led to reduced FC, and more bare soil leads to 
(a)

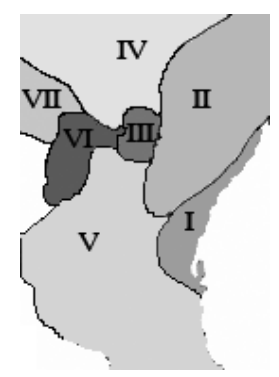

(b)
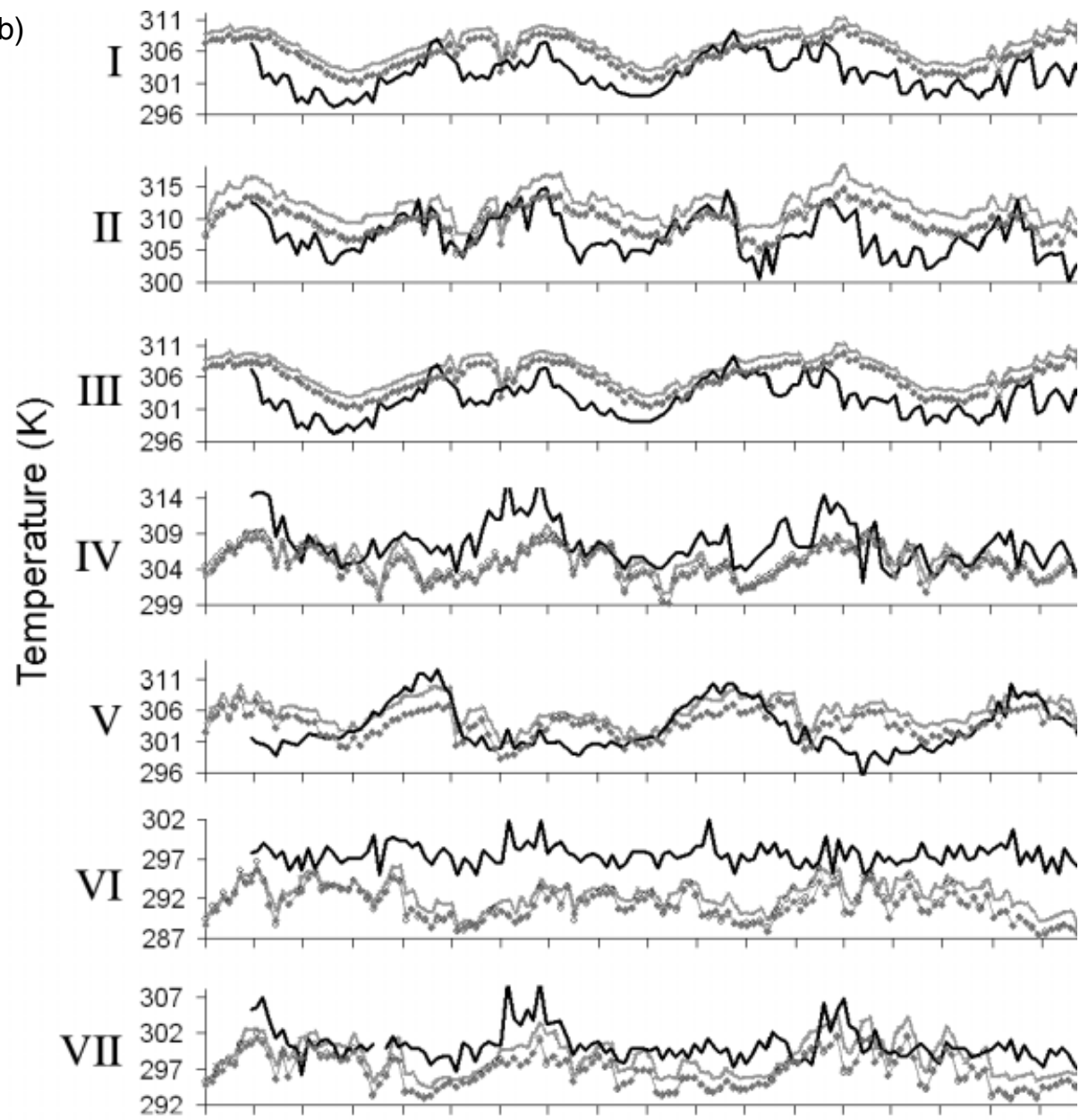

\begin{tabular}{|c|c|c|c|c|c|c|c|c|c|c|c|c|c|c|c|c|c|}
\hline $\begin{array}{l}\because \text { OGE } \\
\because \text { CC } \\
- \text { CCV } \\
- \text { MODIS LST }\end{array}$ & $\begin{array}{l}8 \\
8 \\
8 \\
\text { 익 }\end{array}$ & $\begin{array}{l}8 \\
\stackrel{8}{N} \\
\frac{1}{2}\end{array}$ & 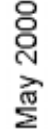 & $\begin{array}{l}8 \\
8 \\
\frac{\mathrm{N}}{3}\end{array}$ & 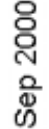 & $\begin{array}{l}\text { O } \\
\text { ํ } \\
\text { 은 }\end{array}$ & $\begin{array}{l}\bar{\delta} \\
\text { ㄱ. } \\
\text { 든 }\end{array}$ & 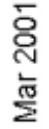 & $\begin{array}{l}\bar{O} \\
\text { d } \\
\text { d }\end{array}$ & $\begin{array}{l}5 \\
\text { 을 } \\
\frac{2}{3}\end{array}$ & 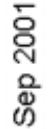 & $\begin{array}{l}\overline{8} \\
\text { 은 } \\
\text { 은 }\end{array}$ & $\begin{array}{l}\text { No } \\
\text { ㄱ. } \\
\text { 득 }\end{array}$ & 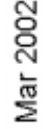 & $\begin{array}{l}\text { N } \\
\text { N } \\
\text { ते }\end{array}$ & $\begin{array}{l}\text { 용 } \\
\text { 족 }\end{array}$ & 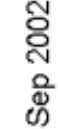 \\
\hline
\end{tabular}

Figure 4. (a) Climate regions adapted from Indeje et al. (2000). (b) Region-averaged 8-day LST for MODIS and the three simulations. The seven regions are taken from the map in (a). Errors occur in seasonality, mean, and range that are attributable to a variety of causes including albedo calibration, model precipitation error, and other factors. MODIS LST accuracy is generally expected to be within $1 \mathrm{~K}$ (Wan 2008). Bimodal rainfall regions are I, II, VI, and VII, and unimodal rainfall regions are III, IV, and V.

higher albedos and lower sensible heat fluxes (SHF). This is evident in Figure 6(c), particularly for May-September when the default LEAF-2 functions give much higher LAI and FC values (note differences in Figure 2 between default and spline functions during this time period).

\subsection{Precipitation}

For validation of precipitation, this study used TRMM 3B42 version 6 data products, which have 3-h temporal resolution and $0.25^{\circ} \times 0.25^{\circ}$ spatial resolution. TRMM data are spatially explicit and well calibrated (Kummerow et al., 2000). For East Africa, TRMM validation has been examined by a few studies. These studies indicate that TRMM has small biases, particularly in the dry seasons (Adeyewa and Nakamura, 2003), although with sparse spatial gauge data. Dinku et al. (2007) showed good performance for TRMM (bias < 10\%) over Ethiopia's complex terrain, which is similar to TRMM validation efforts over West Africa (Nicholson et al., 2003), despite few reference meteorological data available from East 


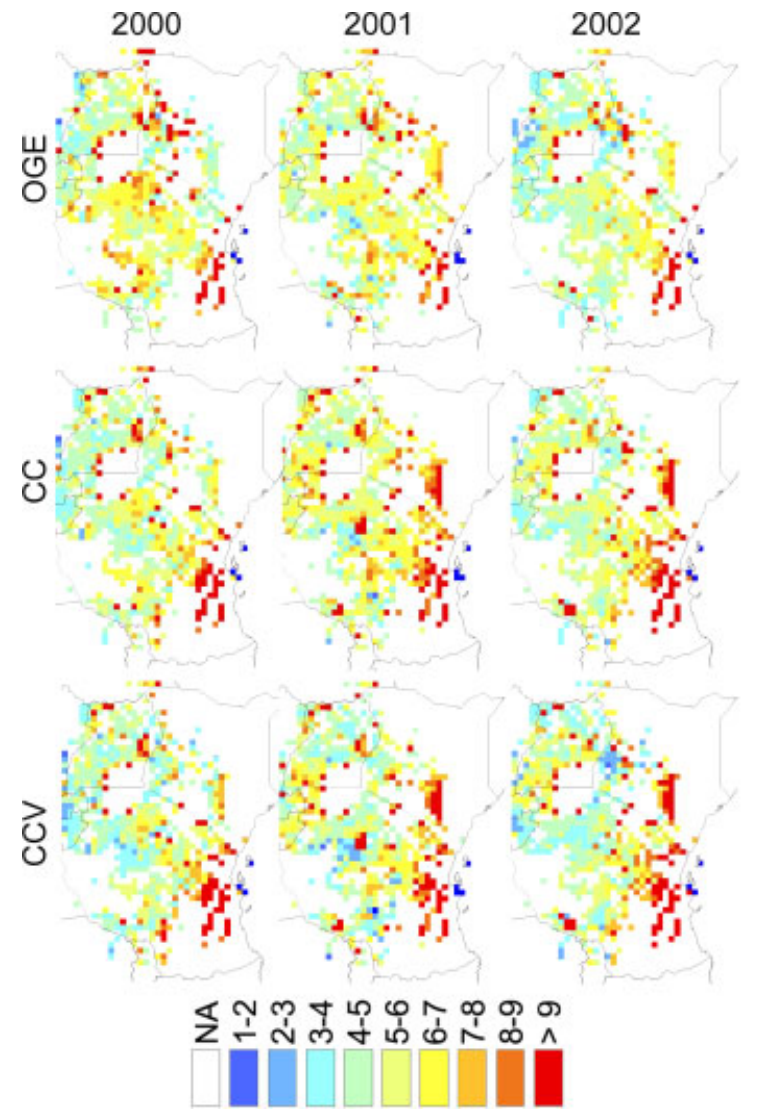

Figure 5. Annual RMS error (K) in simulated LST for each experiment compared to MODIS for agricultural and mixed-use areas only. These were calculated by squaring each 8-day temperature difference for a given year (46 images/year) and averaging the values over time, then taking the square root of that average. Note the strong error reductions (blue areas) around Lake Victoria associated with CLIPcover. This figure is available in colour online at wileyonlinelibrary.com/journal/joc

Africa for validation. Thus, TRMM was selected as the best available reference data source for comparison in this study. RAMS was extensively adjusted to accommodate the complex effects of topography on precipitation and regional microphysical characteristics; thus the differences presented here are not just artefacts of TRMM being different from RAMS. To accommodate the effects of topography and to include more appropriate microphysics parameters, RAMS simulations using the Kain-Fritsch convective parameterisation were run for several trials for 4-month periods (initialised with NCEP soil moisture) with several parameters being changed. The parameter space for Kain-Fritsch adjustments were limited to TOPOCOEF and WLCLELEV variables for finding the combination that resulted in the most accurate monthly rainfall. Microphysics parameters were adjusted to reflect larger and more numerous cloud condensation nuclei associated with biomass burning in the region.

Tables III and IV provide selected precipitation statistics for annual and monthly time periods. From the results in Table III, there were generally small differences in domain-averaged accumulated annual rainfall characteristics, with modest improvements in median and mean rainfall. Perhaps more significant from this table is the improved correlation versus TRMM for the two drier years, supporting the perspective that CLIPcover's more accurate land cover distribution improved temperature and rainfall simulation. Table IV, examining rainfall correlation coefficients month by month, suggests a small but distinct improvement in most months with $\mathrm{CC}$ and $\mathrm{CCV}$ simulations, particularly for CCV during the February-May and October months. These higher correlations during rainy periods suggest that the spline functions improve the model's convective and large-scale rainfall performance. Since the long rains are likely more sensitive than the short rains to land cover parameterisation (and the resulting effects on convective rainfall), we infer that the CCV changes exhibit better improvement during March-May than during the short rains, which are more strongly governed by large-scale dynamics (Okoola, 1999).

Compared to TRMM and other data, RAMS tended to simulate excessive precipitation in some areas, notably

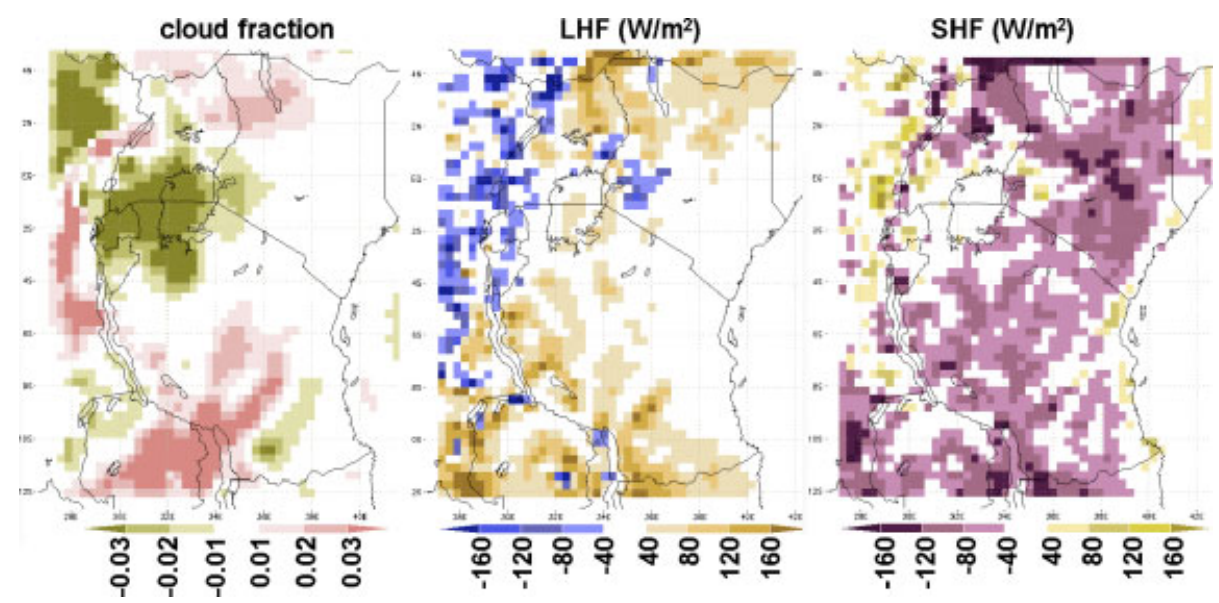

Figure 6. Annual differences (CCV-CC) in (a) cloud fraction, (b) latent heat flux (LHF), and (c) sensible heat flux (SHF) for the year 2000. CCV splines reduced cloudiness around Lake Victoria, increased rainfall (and thus LHF) in southern/western Tanzania and northern Kenya, and increased SHF (thereby increasing LST) throughout much of the domain. This figure is available in colour online at wileyonlinelibrary.com/journal/joc 
Table III. Selected annual precipitation statistics for observed (TRMM) and simulated accumulated rainfall for each year, done over both time and space for the year indicated.

\begin{tabular}{|c|c|c|c|c|c|c|c|c|c|c|c|c|}
\hline & \multicolumn{4}{|c|}{2000} & \multicolumn{4}{|c|}{2001} & \multicolumn{4}{|c|}{2002} \\
\hline & TRMM & OGE & $\mathrm{CC}$ & $\mathrm{CCV}$ & TRMM & OGE & $\mathrm{CC}$ & $\mathrm{CCV}$ & TRMM & OGE & $\mathrm{CC}$ & $\mathrm{CCV}$ \\
\hline Mean (mm) & 55 & 48 & 49 & 50 & 65 & 65 & 66 & 62 & 74 & 73 & 75 & 69 \\
\hline Median (mm) & 45 & 43 & 43 & 46 & 63 & 54 & 55 & 56 & 63 & 50 & 51 & 42 \\
\hline $\mathrm{SD}$ & 33 & 25 & 26 & 30 & 31 & 35 & 36 & 40 & 49 & 51 & 51 & 55 \\
\hline IQR & 50 & 21 & 22 & 37 & 54 & 22 & 23 & 35 & 92 & 50 & 52 & 56 \\
\hline CORR & - & 0.75 & 0.85 & 0.84 & - & 0.57 & 0.62 & 0.63 & - & 0.85 & 0.87 & 0.84 \\
\hline
\end{tabular}

CORR, correlation coefficient with annual accumulated TRMM data; SD, standard deviation; IQR, interquartile range

western Tanzania and Uganda, and undershot January-June rainfall along the Eastern Arc Mountains in southern Tanzania (Figure 7). Some high rainfall patterns stand out where topography is complex, which is likely a result of the Kain-Fritsch scheme which was adjusted to minimise excess events while not causing large errors in rainfall over topographically smoother regions. Rainfall was also under-simulated in eastern Tanzania and along the entire Indian Ocean coast. These areas are major population centres and are also important agricultural areas. Notably, simulated albedo in these areas departed significantly from MODIS albedo, resulting in an underprediction of convection in areas frequented by the coastal sea breeze. However, upland and Lake Victoria precipitation were more accurate; these areas are also major agricultural regions.

Figure 8 illustrates the rainfall averaged for the seven Indeje areas during all 3 years. Long rains precipitation (March-May) was underpredicted generally for Kenyan regions (I-III), also with abbreviated seasons. This figure also suggests that short rains were better simulated in all cases, as CC and/or CCV following the TRMM estimates more closely. As mentioned earlier, the long rains are less predictable than the short rains (Camberlin and Okoola, 2003), and many models have difficulty in simulating the long rains accurately. This difficulty in capturing the erratic quality of the long rains is one possible mechanism for the improvement in simulated rainfall during the latter half of the simulated years. For region I (coastal), the rainy season begins late and ends early. The large grid in the model shows convergence during the rains, the amount of rainfall appears to be lacking. A likely cause for this is a low trigger velocity for the Kuo scheme for areas along the coast; a low value for the trigger would initiate convection earlier and stabilise the atmosphere too early, thus not entraining moisture for a longer time and thus not 'raining out' as much. For region IV (around Lake Victoria), the model overproduces convective rainfall in the inner nested grid (which uses Kain-Fritsch scheme), a trait not uncommon in RAMS 4.4.

Figure 9 illustrates TRMM and simulated precipitation distributions with boxplots. Two interesting features are evident from this figure: increased range and 'whiskers' in $\mathrm{CC}$ and OGE, and the different response with splines for different years as compared to the CC simulation. Particularly in the drier years, long rains and short rains from $\mathrm{CC}$ and $\mathrm{CCV}$ were slightly closer to TRMM estimates than OGE both in terms of median and outlier rainfall. CCV for 2001 and 2002 in particular had fewer extreme values; this more closely matches TRMM estimates, although the simulated rainfall in some regions (e.g. eastern Tanzania) did not match up well with TRMM. CC's improvement over OGE was slight for the domain average, with $\mathrm{CCV}$ changes bringing better overall response. $\mathrm{CCV}$ rainfall, although very similar spatially to $\mathrm{CC}$, exhibited a greater interquartile range and standard deviation (see also Table III), which agrees more closely with TRMM estimates and indicates that these modifications improved model performance for heavier-rainfall events generally. Since a more dynamic phenology pattern could interact more consistently with topographic and other landscape features, it is expected that any green-up consistent with wet-season onset will be captured more effectively with the splines included.

A 3-year aggregated summary of precipitation differences relative to TRMM across the study domain in Figure 10 shows 3-year median rainfall differences mapped over regions that meet the $5 \%$ level of confidence (based on the Wilcoxon test with the Bonferroni adjustment; Holm, 1979; Legendre and Legendre, 1998); median monthly rainfall is often a more useful measure than mean rainfall. Overall spatial patterns are similar for three simulations, although in parts of northwestern Kenya, relatively larger median differences (cyan pixels) suggest that a different precipitation distribution exists for CCV compared to the other simulations. Thus although Figure 9 shows overall improvement in rainfall simulation, some areas witness a slight decline in rainfall reproduction.

\section{Discussion}

The adaptation of MODIS data using spline functions improved model's reproduction of LST and precipitation for the growing seasons. Annual domain-averaged precipitation and LST improved only modestly, but growingseason errors were reduced, particularly with the addition 


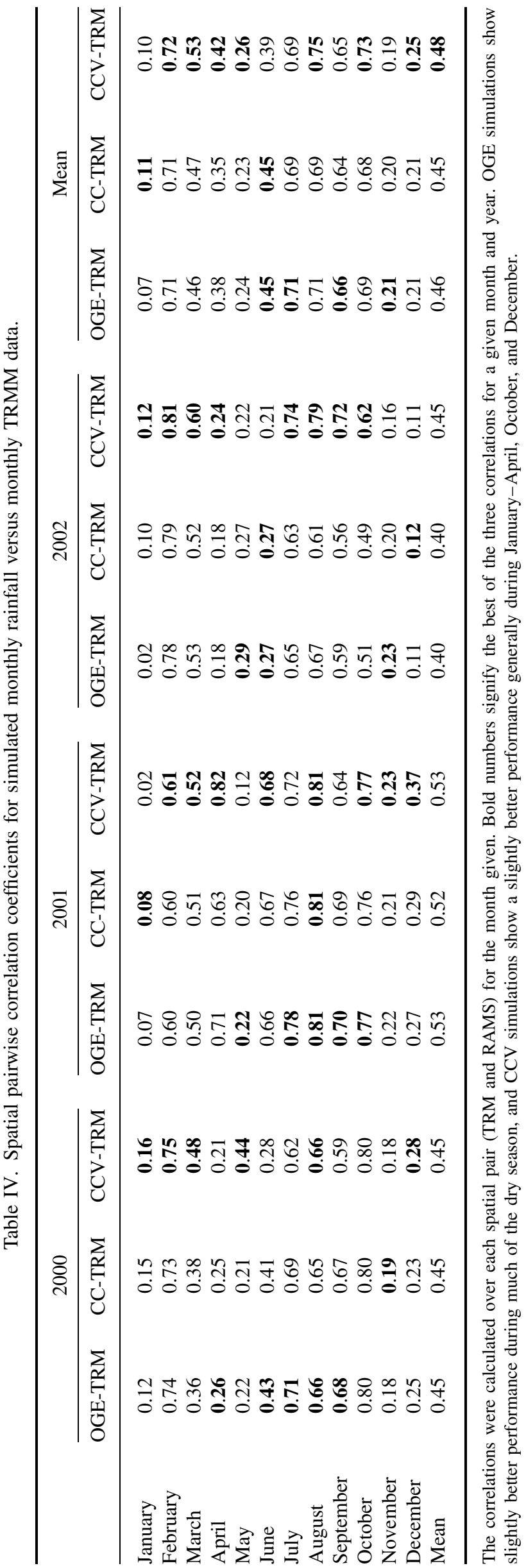

of ClipCover, and further with the addition of spline functions of LAI and FC. The domain-averaged CCV simulations appear to be more accurate for drier conditions, partly related to the high 'greenness' of the default functions. In addition to the domain-averages, $\mathrm{CC}$ and $\mathrm{CCV}$ adjustments were found to improve model performance over the OGE/defaults particularly in areas dominated by agriculture. An increase in LST error was found in pastoral areas in some parts of Tanzania, particularly during wet conditions; yet, the CCV improvements also resulted in large reductions in LST error over CC in major agricultural areas surrounding Lake Victoria.

The LS02 and Ge et al. (2007) approach are an important first step in the integration of remotely sensed biophysical data into the simulation of land-climate interactions. However, when seasonality of features is not known (e.g. for future scenario simulations), using data from one year as a driver for phenology in a different year is likely inappropriate for capturing the broad natural variability across seasons. Developing processbased phenology models (instead of statistical models) is likely to improve performance, but such an approach is data-intensive, requires in situ data for validation, and requires considerable time and cost; so our simpler approach has considerable merits. Other studies (Parton et al., 1998; Lu et al., 2001) show promise working in this direction, and an effective merger of remotely sensed data and process-based plant physiology models is clearly needed by these studies.

Both changes - regional land cover and regional phenologies - produced distinct and separate improvements in model performance. The performance improvement as measured by RMS error is modest when analysed at annual scales but shows more promise at monthly timescales. Importantly, error is reduced during the main growing seasons. CLIPcover in particular dramatically improved modelled LST in the major agricultural areas, which are also densely populated - notably in Uganda - and represents an important advancement for the integrated studies of climate, tropical agriculture, and food security. There are a variety of ways to implement splines, and this particular construction may have possibilities for significant improvement. It should also be noted that 'tuning' RAMS to more accurately produce precipitation and LST for East African landscapes may narrow the generalisability of these results; this 'parameter space' of outcomes dependent on tuning would benefit from further exploration.

The error in semi-arid regions (Figure 5) is in large part a consequence of the highly variable open savannah landscapes and coastal forests (note land cover differences in Figure 1) where the albedo, LAI, and FC vary dramatically over time. This variability is complex and difficult to accurately resolve in a regional climate model; moreover, there is significant error associated with classifying the landscapes used to extract the LAI and FC data. From Figure 5 we see that the high OGE error in northern Kenya was reduced with CC and CCV while the error in central Tanzania grew. For the wet year 2002, the 


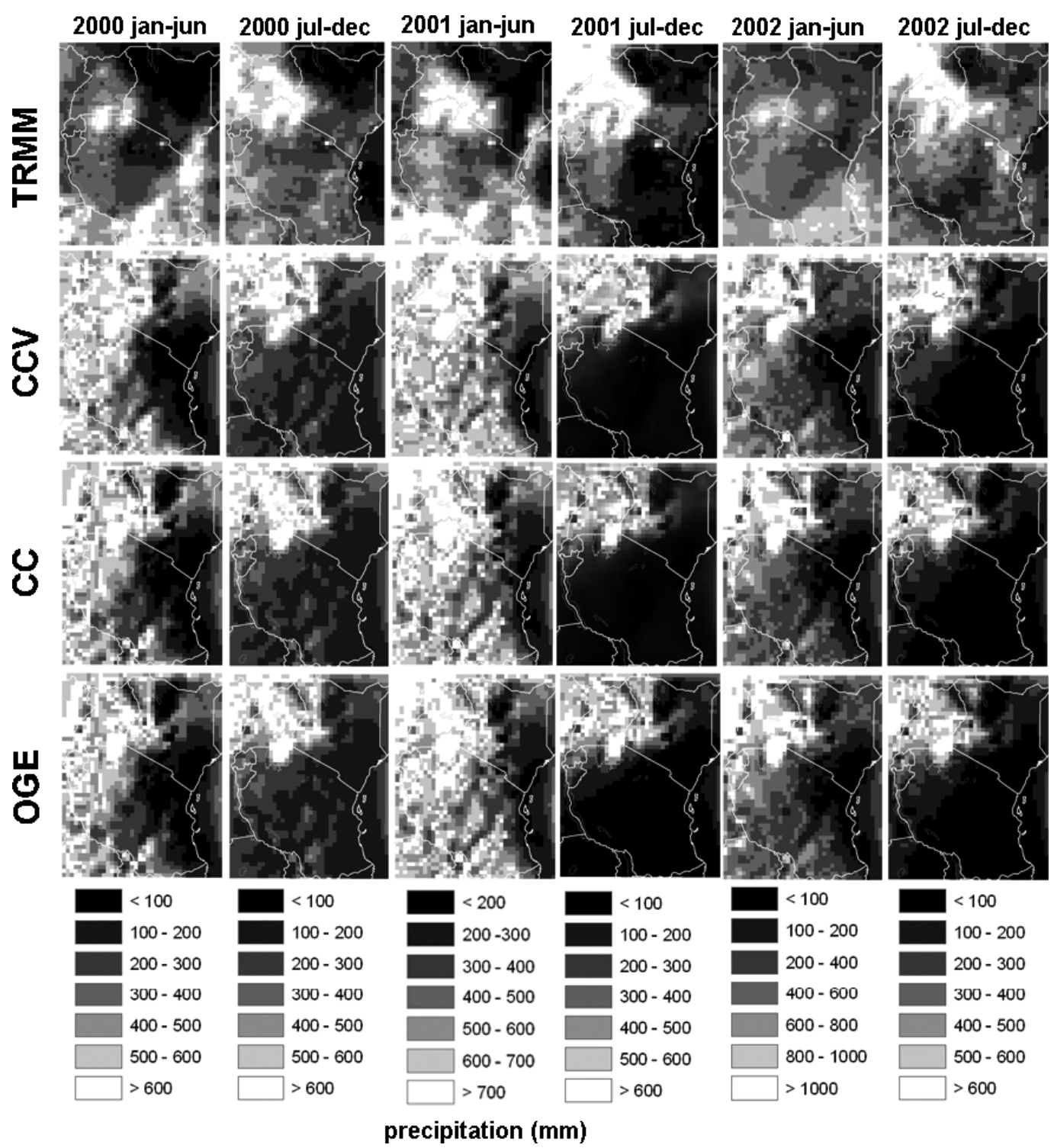

Figure 7. Accumulated rainfall for TRMM and for the three simulations for the three years considered, separated into January-June and July-December segments to capture seasonality. Note that scales are not all the same for each time period.

overall spatial RMS error in OGE was similar to CC and $\mathrm{CCV}$, although distributed quite differently spatially. This is because the rather 'green' default LAI and FC more suitably reflect phenologies that are saturated during a wet year than do the 3-year-average splines (see example in Figure 2). Evidently, as one compares Figures 4 and 5 , the splines perform better both temporally and spatially for average-rainfall and low-rainfall years. In many regions, the deviation of CCV from MODIS diminished during the dry season although being very similar to that of $\mathrm{CC}$ and OGE during the short rains (e.g. Figure 4, region V). Since the spline simulations show a distinct response to each year, with LST differences from CC increasing for wetter years, we conclude that a more accurate landscape also needs to be accompanied by accurate and perhaps rainfall-sensitive phenological information.

Regionally appropriate land cover with remotely sensed FC and LAI are only two of a large number of potential sources of error in representing the land surface in regional climate models. Some errors in the land surface parameterisations described here are related to other variables not explored in this study, most notably albedo. Changes at the farm/plot scale are likely negligible as microscale processes tend to be 'mixed away' by boundary layer turbulence and other larger scale processes. The persistent seasonal under- and overprediction of LST suggests that albedo or similar factors that influence the surface energy budget may introduce consistent biases in the simulations. The single-year MODIS imports available for more recent versions of RAMS (e.g. RAMS 6) cannot be used as effectively for future simulations because phenology varies so significantly from year to year. Our results suggest the need for other improvements in biophysical parameters beyond LAI and FC, possibly, with a more climate-driven spline that allows for vegetation greening/senescence or similar process-based representations. 


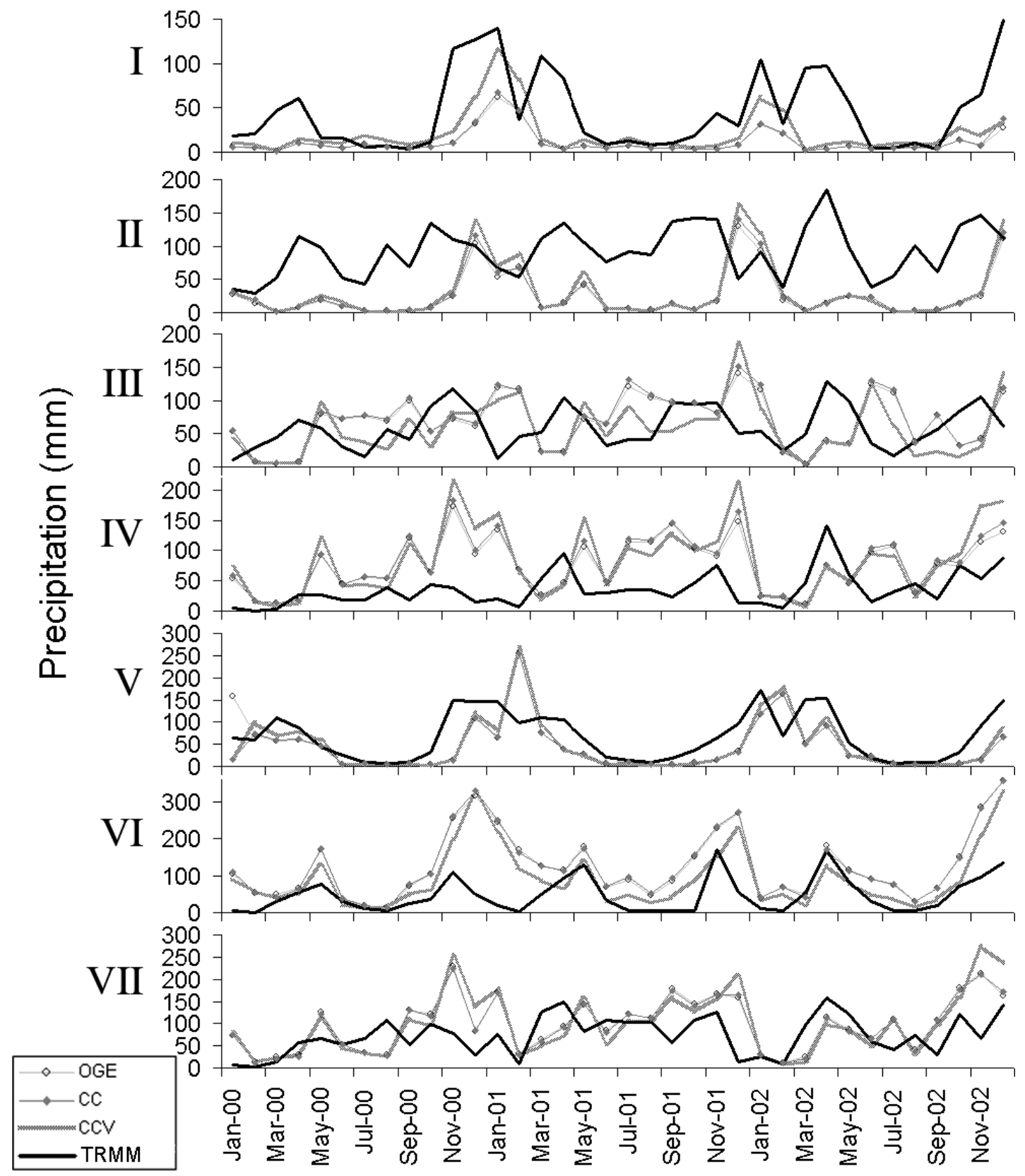

Figure 8. Domain-averaged monthly precipitation for TRMM and the three simulated cases, by the same regions for Figure 4. Source: Adapted from Indeje et al. (2000).

Greater accuracy in the modelled estimation of precipitation and temperature can be achieved by employing seasonally accurate phenological information. Remotely sensed imagery could help better characterise varying years (drought, wet, normal), if some index of wetness could be tracked in RAMS. Our results, combined with Ge et al. (2007), point to the need for incorporation of satellite-observed vegetation phenologies that are also sensitive to the general climate state. A hybrid of these approaches points to further potential improvement: high-resolution phenology schemes that are dependent on in situ climate conditions (as with real vegetation) when the climate state (e.g. soil moisture, cloudiness, temperature) is not already known. Further work is needed to adapt and join remotely sensed information with biophysical representations in climate models so that simulations driven by non-historical boundary conditions (e.g. future scenarios) can exhibit a more accurate coupling between the landscape and the atmosphere.

\section{Acknowledgements}

The images and data used in this study were acquired using the GES-DISC Interactive Online Visualization ANd aNalysis Infrastructure (Giovanni) as part of the NASA's Goddard Earth Sciences (GES) Data and Information Services Center (DISC). This research was supported by NSF Grant 0308420, Biocomplexity/CNH. NCEP reanalysis data were provided by the NOAA/OAR/ 


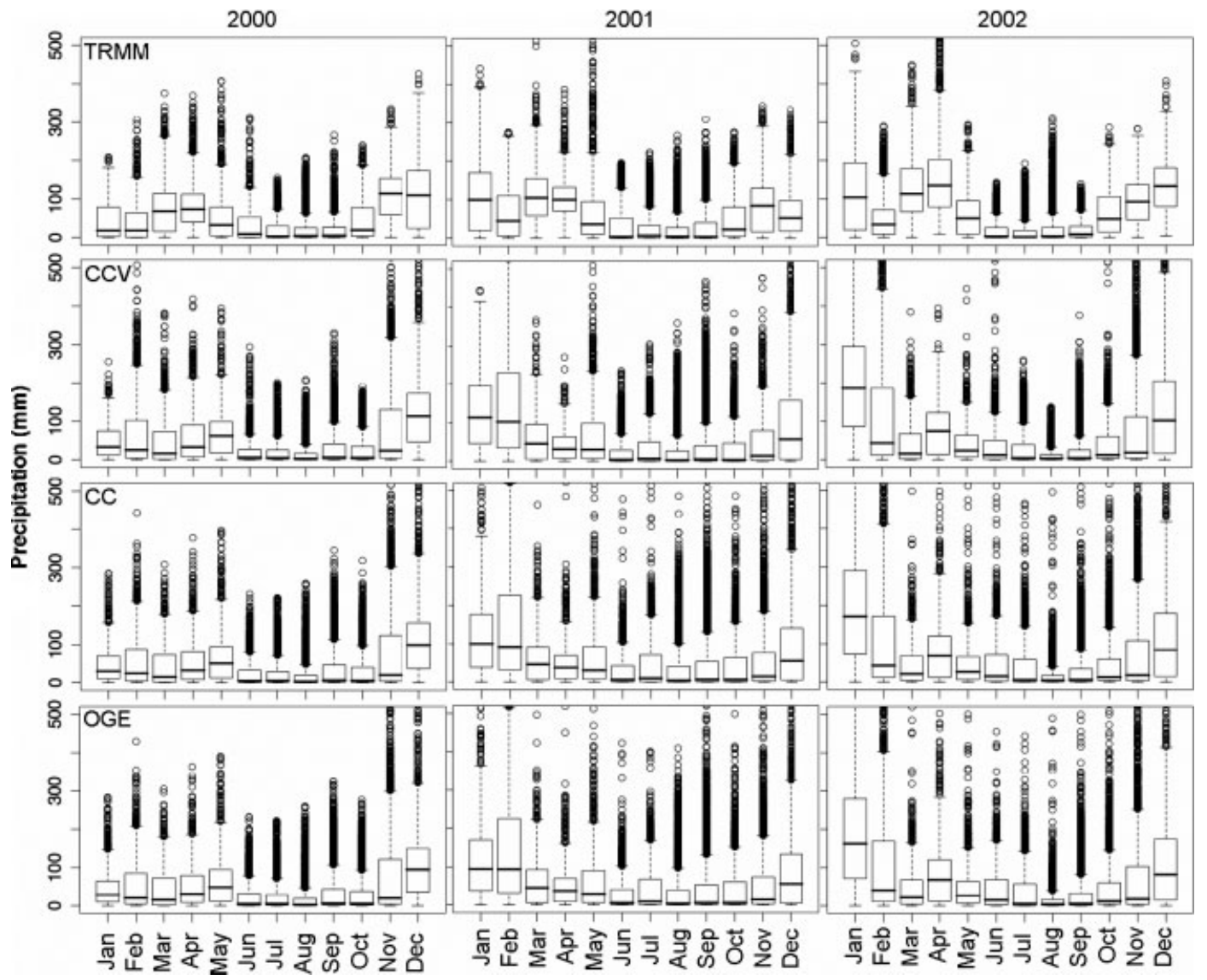

Figure 9. Boxplots of monthly precipitation by year for TRMM and the three simulations. Note different scale for 2002. Box boundaries are from $25 \%$ to $75 \%$, and whiskers are $5 \%$ to $95 \%$ of the data distribution. Circles are extreme outliers.

\section{simulation, some areas witness a slight decline in rainfall reproduction.}

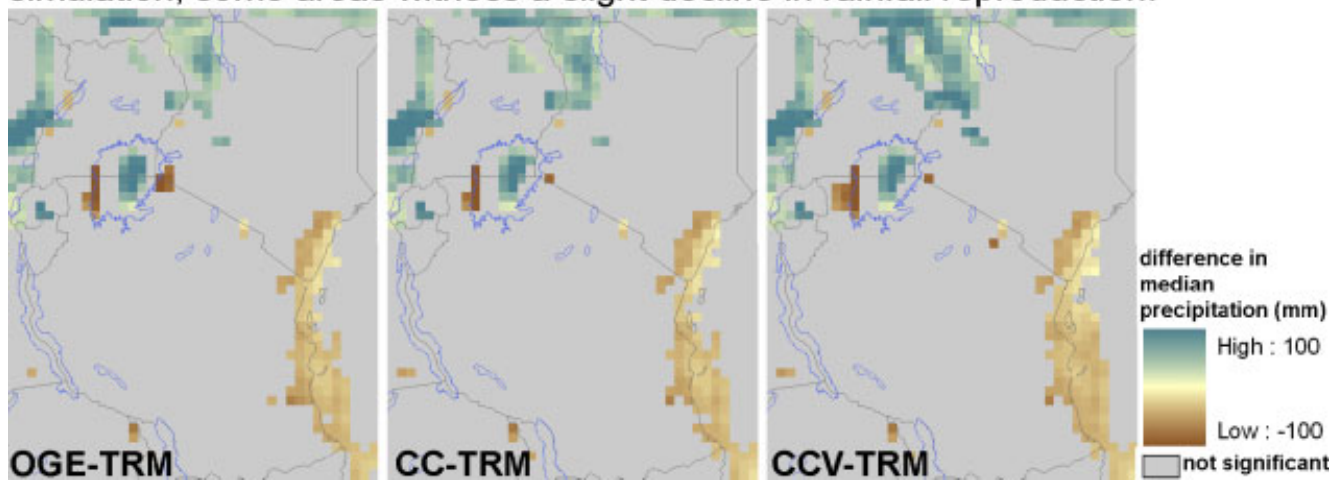

Figure 10. Difference in median precipitation for 3-year simulated and TRMM rainfall data. Grey area indicates no significant difference (mapped over regions that meet the $5 \%$ level based on the non-parametric Wilcoxon test; grey indicates regions that do not meet this threshold). This figure is available in colour online at wileyonlinelibrary.com/journal/joc

ESRL PSD, Boulder, Colorado, USA, from their website http://www.cdc.noaa.gov/. We are also grateful to Richard Anyah for advice in adapting a lake model for RAMS.

\section{References}

Adeyewa ZD, Nakamura K. 2003. Validation of TRMM radar rainfall data over major climatic regions in Africa. Journal of Applied Meteorology 42: 331-347.
Anyah RO, Semazzi FHM, Xie L. 2006. Simulated physical mechanisms associated with multi-scale climate variability over Lake Victoria Basin in East Africa. Monthly Weather Review 134: 3588-3609.

Barnes CA, Roy DP. 2008. Radiative forcing over the conterminous United States due to contemporary land cover land use albedo change. Geophysical Research Letters 35: L09706. DOI:10.1029/2008GL033567.

Behera SK, Luo JJ, Masson S, Yamagata T, Delecluse P, Gualdi S, Navarra A. 2005. Paramount impact of the Indian Ocean dipole on the east African short rains: a CGCM study. Journal of Climate 18: 4514-4453.

Black E, Slingo J, Sperber K. 2003. An observational study of the Relationship between excessively strong short trains in coastal East Africa and Indian Ocean SST. Monthly Weather Review 131: 74-94. 
Camberlin P, Okoola RE. 2003. The onset and cessation of the "long rains" in eastern Africa and their interannual variability. Theoretical and Applied Climatology 75: 43-45.

Camberlin P, Planchon O. 1997. Coastal precipitation regimes in Kenya. Geografiska Annaler, Series A-Physical Geography 79A(1-2): 109-119.

Carleton AM, Travis D, Arnold D, Brinegar R, Jelinski DE, Easterling DR. 1994. Climatic-scale vegetation-cloud interactions during drought using satellite data. International Journal of Climatology 14(6): $593-623$

Chen C, Cotton WR. 1987. The physics of the marine stratoscumuluscapped mixed layer. Journal of Atmospheric Science 44: 2951-2977.

Clapp RB, Hornberger GM. 1978. Empirical equations for some soil hydraulic properties. Water Resources Research 14: 601-604.

Conway D, Hanson CE, Doherty R, Persechino A. 2007. GCM simulations of the Indian Ocean dipole influence on East African rainfall: present and future. Geophysical Research Letters 34: L03705, DOI:10.1029/2006GL027597.

Cotton W, Pielke R, Walko R, Liston G, Tremback C, Jiang H, McAnelly R, Harrington J, Nicholls M, Carrio C, McFadden J. 2003. RAMS 2001: Current status and future directions. Meteorology and Atmospheric Physics 82: 5-29.

Crutzen PJ, Stoermer EF. 2000. The "Anthropocene". Global Change Newsletter 41: 12-13.

Deardorff JW. 1978. Efficient prediction of ground surface temperature and moisture, with inclusion of a layer of vegetation. Journal of Geophysical Research 83: 1889-1903.

Diffenbaugh NS, Pal JS, Trapp RJ, Giorgi F. 2005. Fine-scale processes regulate the response of extreme events to global climate change. Proceedings of National Acadamy of Sciences of the United States of America 102(44): 15774.

Di Gregorio A, Jansen LJM. 2005. Land Cover Classification System: Classification Concepts and User Manual. Food and Agriculture Organization of the United Nations: Rome

Dinku T, Ceccato P, Grover-Kopec E, Lemma M, Connor S, Ropelewski CF. 2007. Validation of satellite rainfall products over East Africa's complex topography. International Journal of Remote Sensing 8(7): 1503-1526.

Foley J, DeFries R, Asner GP, Barford CG, Bonan GB, Carpenter SR, Chapin FSI, Coe MT, Daily G, Gibbs H, Helkowski JH, Holloway T, Howard E, Kucharik C, Monfreda C, Patz J, Prentice IC, Ramankutty N, Snyder PK. 2005. Global consequences of land use. Science 309: 570-574

Ge J, Qi J, Lofgren B, Moore N, Torbick N, Olson J. 2007. Impacts of land use/cover classification accuracy on regional climate simulations. Journal of Geophysical Research 112: DOI:10.1029/2006JD007404

Ge J, Qi J, Torbick N. 2005. Biophysical evaluation of five land covers for land climate interaction modeling in East Africa, Proceedings at the 25th International Geoscience and Remote Sensing Symposium, 25-29 July 2005, IEEE International, Seoul, Korea.

Gutman G, Ignatov A. 1998. The derivation of the green vegetation fraction from NOAA/AVHRR data for use in numerical weather prediction models. International Journal of Remote Sensing 19: $1533-1543$.

Hales K, Neelin J, Zeng N. 2004. Sensitivity of tropical land climate to leaf area index: role of surface conductance versus albedo. Journal of Climate 17: 1459-1473.

Holm S. 1979. A simple sequentially rejective multiple test procedure. Scandinavian Journal of Statistics 6: 65-70.

Hostetler SW, Bates GT, Giorgi F. 1993. Interactive coupling of a lake thermal model with a regional climate model. Journal of Geophysical Research 98(D3): 5045-5057.

Huang JZ. 2003. Local asymptotics for polynomial spline regression. Annanls of Statistics 31: 1600-1635.

Huete A, Miura T, Rodriguez E, Gao X, Ferreira L. 2002. Overview of the radiometric and biophysical performance of the MODIS vegetation indices. Remote Sensing of Environment 83: 195-213. Didan, $\mathrm{K}$.

Indeje M, Anyamba EK. 1998. Sensitivity of mesoscale systems over Kenya to changes in roughness length. Journal of African Meteorological Society 3: 19-33.

Indeje M, Semazzi FHM, Ogallo LJ. 2000. ENSO signals in East African rainfall seasons. International Journal of Climatology 20: $19-46$.

Jin M, Dickinson RE, Vogelmann AM. 1997. A comparison of CCM2BATS skin temperature and surface-air temperature with satellite and surface observations. Journal of Climate 10: 1505-1524.
Justice CO, Townshend J. 2002. Special issue on the moderate resolution imaging spectroradiometer (MODIS): a new generation of land surface monitoring. Remote Sensing of Environment 83(1): $1-2$

Kain JS, Fritsch JM. 1993. Convective parameterization for mesoscale models: The Kain-Fritsch scheme. In The Representation of Cumulus Convection in Numerical Models, Meteorological Monograph, vol. 24. American Meteorological Society: Boston; 165-170.

Kalnay E, Kanamitsu M, Kistler R, Collins W, Deaven D, Gandin L, Iredell M, Saha S, White G, Woollen J, Zhu Y, Chelliah M, Ebisuzaki W, Higgins W, Janowiak J, Mo KC, Ropelewski C, Wang J, Leetmaa A, Reynolds R, Jenne R, Joseph D. 1996. The NCEP/NCAR 40-year reanalysis project. Bulletin of the American Meteorological Society 77: 437-470.

Knyazikhin Y, Glassy YJ, Privette JL, Tian Y, Lotsch A, Zhang Y, Wang Y, Morisette JT, Votava P, Myneni RB, Nemani RR, Running SW. 1999. MODIS Leaf Area Index (LAI) and Fraction of Photosynthetically Active Radiation Absorbed by Vegetation (FPAR) product (MOD15) algorithm theoretical basis document, http://eospso.gsfc.nasa.gov/atbd/modistables.html.

Kummerow C, Simpson J, Thiele O, Barnes W, Chang ATC, Stocker E, Adler RF, Hou A, Kakar R, Wentz F, Ashcroft P, Kozu T, Hong Y, Okamoto K, Iguchi T, Kuroiwa H, Im E, Haddad Z, Huffman G, Ferrier B, Olson WS, Zipser E, Smith EA, Wilheit TT, North G, Krishnamurti T, Nakamura K. 2000. The status of the tropical rainfall measuring mission (TRMM) after two years in orbit. Journal of Applied Meteorology 39: 1965-1982.

Latham J. 2001. AFRICOVER east Africa. LUCC Newlsetter 7: 15-16.

Latif M, Dommenget D, Dima M, Grotzner A. 1999. The role of Indian Ocean sea surface temperature in forcing East African rainfall anomalies during December-January 1997/98. Journal of Climate 12: $3497-3504$.

Lawrence PJ, Chase TN. 2007. Representing a new MODIS consistent land surface in the Community Land Model (CLM 3.0) Journal of Geophysical Research-Biogeoscience 112: G01023, DOI:10.1029/2006JG000168

Legendre P, Legendre L, 1998. Numerical ecology. In Developments in Environmental Modelling. Elsevier: Amsterdam; 20.

Lofgren BM. 1995. Sensitivity of land-ocean circulations, precipitation, and soil moisture to perturbed land surface albedo. Journal of Climate 8: 2521-2542.

Lu L, Pielke RA Sr., Liston GE, Parton WJ, Ojima D, Hartman M. 2001. Implementation of a two-way interactive atmospheric and ecological model and its application to the central United States. Journal of Climate 14: 900-919.

Lu L, Shuttleworth WJ. 2002. Incorporating NDVI-Derived LAI into the climate version of RAMS and its impact on regional climate. Journal of Hydrometeorology 3: 347.

Marland G, Pielke RA Sr., Apps M, Avissar R, Betts RA, Davis KJ, Frumhoff PC, Jackson ST, Joyce L, Kauppi P, Katzenberger J, MacDicken KG, Neilson R, Niles JO, Sutta D, Niyogi S, Norby RJ, Pena N, Sampson N, Xue Y. 2003. The climatic impacts of land surface change and carbon management, and the implications for climate-change mitigation policy. Climate Policy 3: 149-157.

Mayaux P, Bartholomé E, Fritz S, Belward A. 2004. A new land-cover map for Africa for the year 2000. Journal of Biogeography 31: 861-877.

Mellor GL, Yamada T. 1982. Development of a turbulence closure model for geophysical fluid problems. Reviews of Geophysics $\mathbf{2 0}$ $851-875$

Moore N, Rojstaczer S. 2002. Irrigation's influence on precipitation: Texas High Plains, U.S.A. Geophysical Research Letters 29: 2.1-2.4 Nicholson SE, Some B, McCollum J, Nelkin E, Klotter D, Berte Y, Diallo BM, Gaye I, Kpabeba G, Ndiaye O, Noukpozounkou JN Tanu MM, Thiam A, Toure AA, Traore AK. 2003. Validation of TRMM and other rainfall estimates with a high-density gauge dataset for West Africa. Part II: validation of TRMM rainfall products. Journal of Applied Meteorology 42: 1355-1367.

Oettli P, Camberlin P. 2005. Influence of topography on monthly rainfall distribution over East Africa. Climate Research 28: 199-212.

Oglesby RJ, Marshall S, Erickson DJ, Roads JO, Robertson FR. 2002. Thresholds in atmosphere-soil moisture interactions: results from climate model studies. Journal of Geophysical ResearchAtmospheres 107: 1029-1045.

Okoola RE. 1999. Midtropospheric circulation patterns associated with extreme dry and wet episodes over equatorial eastern Africa during the Northern Hemisphere spring. Journal of Applied Meteorology 38: 1161-1169. 
Olson JM, Alagarswamy G, Andresen J, Campbell D, Ge J, Davis A, Huebner M, Lofgren B, Lusch D, Moore N, Pijanowski B, Qi J, Thornton P, Torbick N, Wang J. 2007. Integrating diverse methods to understand climate-land interactions in East Africa. Geoforum, DOI:10.1016/j.geoforum.2007.03.011.

Olson J, Watts J, Allison L. 1985. Major World Ecosystem Complexes Ranked by Carbon in Live Vegetation: A Database, NDP-017. Carbon Dioxide Information Center, Oak Ridge National Laboratory: Oak Ridge.

Oyama MD, Nobre CA. 2003. A new climate-vegetation equilibrium state for Tropical South America. Geophysical Research Letters 30: 2199-2203.

Parton WJ, Hartman M, Ojima D, Schimel D. 1998. DAYCENT and its land surface submodel: description and testing. Global and Planetary Change 19(1): 35-48.

Pielke RA Sr., Cotton WR, Walko RL, Tremback CJ, Lyons WA, Grasso LD, Nicholls ME, Moran MD, Wesley DA, Lee TJ, Copeland JH. 1992. A comprehensive meteorological modeling system - RAMS. Meteorology and Atmospheric Physics 49: 69-91.

Pitman AJ. 2003. The evolution of, and revolution in, land surface schemes designed for climate models. Internatioal Journal of Climatology 23(15): 479-510.

Plisnier P-D, Serneels S, Lambin EF. 2000. Impact of ENSO on East African ecosystems: a multivariate analysis based on climate and remote sensing data. Global Ecology and Biogeography 9(6): 481-497.

Pohl B, Camberlin P, Roucou P. 2005. Typology of pentad circulation anomalies over the Eastern Africa-Western Indian Ocean region, and their relationship to rainfall. Climate Research 29: 111-127.

Qi J, Kerr Y, Moran MS, Weltz M, Huete AR, Sorooshian S, Bryant R. 2000. Leaf area index estimates using remotely sensed data and BRDF models in a semi-arid region. Remote Sensing of Environment 73: $18-30$.

Rabin RM, Stadler S, Wetzel PJ, Stensrud DJ, Gregory M. 1990. Observed effects of landscape variability on convective clouds. Bulletin of the American Meteorological Society 71: 272.

Reynolds RW, Rayner NA, Smith TM, Stokes DC, Wang W. 2002. An improved in situ and satellite SST analysis for climate. Journal of Climate 15: 1609-1625.

Roy SB, Avissar R, 2002. Impact of land use/land cover change on regional hydrometeorology in Amazonia. Journal of Geophysical Research 107(D20): 8037, DOI:10.1029/2000JD000266.

Schreck CJ III, Semazzi FHM. 2004. Variability of the recent climate of Eastern Africa. International Journal of Climatology 24: 681-701.

Seneviratne SI, Luthi D, Litschi M, Schar C. 2006. Land-atmoshpere coupling and climate change in Europe. Nature 443: 205, DOI:10.1038/nature05095.

Sun L, Semazzi FHM, Giorgi F, Ogallo L. 1999. Application of the NCAR regional climate model to eastern Africa. Part II: simulations of interannual variability. Journal of Geophysical Research 104(D6): $6549-6562$

Torbick N, Lusch D, Olson J, Ge J, Qi J. 2005. An assessment of Africover and GLC2000 using general agreement and airborne, Proceedings of the $25^{\text {th }}$ International Geoscience and Remote Sensing Symposium, 25-29 July 2005, IEEE International, Seoul, Korea.

Torbick N， Lusch D, Qi J, Moore N， Olson JM， Ge J. 2006. Developing land use/land cover parameterization for climate-land modeling in East Africa. International Journal of Remote Sensing 27: 4227-4244.

Tremback CJ, Kessler R. 1985. A surface temperature and moisture parameterization for use in mesoscale numerical models, Preprints, Seventh Conference on Numerical Weather Prediction, American Meteor Society, Montreal, Canada, 148-151.

Voldoire A, Eickhout B, Schaeffer M, Royer J-F, Chauvin F. 2007. Climate simulation of the $21^{\text {st }}$ century with interactive land-use changes. Climate Dynamics 29: 177-193.

Walko RL, Band LE, Baron J, Kittel TGF, Lammers R, Lee TJ, Ojima D, Pielke RA, Taylor C, Tague C, Tremback CJ, Vidale PL. 2000. Coupled atmosphere-biophysics-hydrology models for environmental modeling. Journal of Applied Meteorology 39: 931-944.

Wan Z. 2008. New refinements and validation of the MODIS land-surface temperature/emissivity products. Remote Sensing of Environment 112: 59-74.

Wan Z, Wang P, Li X, Wan Z. 2004a. Using MODIS land surface temperature and normalized difference vegetation index for monitoring drought in the southern Great Plains, USA. International Journal of Remote Sensing 25: 61-72.

Wan Z, Zhang Y, Zhang Q, Li ZL. 2002. Validation of the land-surface temperature product retrieved from Terra Moderate Resolution Imaging Spectroradiometer data. Remote Sensing of Environment 83(1-2): $163-180$.

Wan Z, Zhang Y, Zhang Q, Li Z-L. 2004b. Quality assessment and validation of the MODISglobal land-surface temperature. International Journal of Remote Sensing 25(1): 261-274.

Wang Y, Woodcok CE, Buermann W, Stenberg P, Voipio P, Smolander H, Hame T, Tian Y, Hu J, Knyazikhin Y, Myneni RB. 2004. Evaluation of the MODIS LAI algorithm at a coniferous forest site in Finland. Remote Sensing of Environment 91: 114.

Wang J, Yang L. 2009. Polynomial spline confidence bands for regression curves. Statistica Sinica 29: 325-342.

Weaver CP, Avissar R. 2001. Atmospheric disturbances caused by human modification of the landscape. Bulletin of the American Meteorological Society 82: 269-281.

Weaver CP, Roy SB, Avissar R. 2002. Sensitivity of simulated mesoscale atmospheric circulations resulting from heterogeneity to aspects of model configuration. Journal of Geophysical Research 107(D20): 8041, DOI:10.1029/2001JD000376. 